DOI: $10.52950 / E S .2021 .10 .2 .008$

\title{
STUDY OF INTERTEMPORAL DISCOUNTING ACCORDING TO AGE GROUPS
}

\author{
JIRI ROTSCHEDL, HELENA MITWALLYOVA
}

\begin{abstract}
:
The paper focuses on the topic of intertemporal discounting of individuals according to age groups. Using the sample of examined individuals, it aims to verify the hypothesis that the patience of individuals decreases with their increasing age. The study included a total of 599 individuals with an average age of 38.3 years (min. 16 and max. 82 years) who answered classical questions focused on time discounting and impulsive behaviour. In total, four possible scenarios were analysed: a small reward (CZK 100) with a delay of 1 day, a small reward with a delay of 1 month, a large reward (CZK $100,000)$ with a delay of 1 day and a large reward with a delay of 1 month. The delayed reward was always increased by $10 \%$ (i.e., CZK 110 or CZK 110,000). The basic hypothesis was that with increasing age, the subjective discount rate increases i.e., patience decreases. The above-mentioned 4 scenarios were evaluated for the hypotheses, while only three of the four scenarios were confirmed for all hypotheses. The results in the examined individuals suggest that with increasing age, there is a decrease in patience and at the same time a decrease in impulsive behaviour. These findings may have an overlap in consumption or savings in relation to the aging population.
\end{abstract}

\section{Keywords:}

subjective discount rate, individual decision making, impulsive behaviors, age groups

JEL Classification: D12, D91

\section{Authors:}

JIRI ROTSCHEDL, Prague University of Economics and Business, Czech Republic, Email: jiri.rotschedI@vse.cz HELENA MITWALLYOVA, Prague University of Economics and Business, Czech Republic, Email: helena.mitwallyova@vse.cz

\section{Citation:}

JIRI ROTSCHEDL, HELENA MITWALLYOVA (2021). Study of Intertemporal Discounting According to Age Groups. International Journal of Economic Sciences, Vol. X(2), pp. 127-140., 10.52950/ES.2021.10.2.008 


\section{Introduction}

The issue of discounting has been the subject of several studies for almost 200 years. John Rae's "The Sociological Theory of Capital" (1834) may be considered one of the first works on this topic. With the advent of mathematisation of economy, and thus with exponential (Samuelson, 1937) or hyperbolic (Ainslie, 1975; Herrnstein, 1981; Loewenstein, Prelec, 1992) models of discounting, experimental studies have been developed created to verify these theoretical models of discounting.

Important works concerning this issue also include the experiments and research of $D$. Kahneman and A. Tversky. In their psychological experiments, they demonstrated a discrepancy between models and actual decisions of individuals. It is worth noting their prospectus theory (Kahneman D. and Tversky A., 1979) and work focused on loss aversion (Kahneman D. and Tversky A., 1991), as well as "framing" (Kahneman D. and Tversky A., 1984) and other psychological aspects influencing the individual's decision-making.

Intertemporal discounting is certainly not constant throughout life, as discussed in several experiments and studies: Green et al (1994); Whelan R., McHugh L. A. (2010); Halfmann K., Hedgcock W., Denburg N. L. (2013); Li Y., Baldassi M., Johnson E. J., Weber E. U. (2013); or Richter D., Mata R. (2018). However, some studies have not confirmed differences in reward discounting in the older or younger generation: Harrison G. W., Lau M. I., Williams M. B. (2002); Read, D. \& Read N. L. (2004); Samanez-Larkin et al (2011); or Roalf D. R., Mitchell S. H., Harbaugh W. T., Janowsky J. S. (2012).

Individuals' approach to reward discounting plays an important role in macroeconomic models with an impact on savings or consumption. Differences in discounting between generations may therefore affect savings or consumption in the economy in relation to the population aging. Compared to younger individuals, decisions of older individuals may also differ due to a decline in the cognitive capacities of older people. When making their decisions, they can achieve worse results, especially if the choices are cognitively demanding, as described by Liu, P., Wood, S., Hanoch, Y. (2015). The influence on age-related decision-making may have a purely neurological cause.

This paper aims to experimentally verify whether reward discounting differs between different age categories. Some authors have demonstrated in their experiments the association of discounting and age in the shape of the letter "U": Richter D., Mata R. (2018). Similar results may be consistent with the life cycle theory (Modigliani F., 1966) or permanent income theory (Friedman M., 1957).

\section{Methods Respondents}

The survey aimed at finding reward discounting was conducted on a total of 615 respondents in different age groups, genders, and education levels. The sample of respondents includes a total of 404 women (65.69\%) and 211 men (34.31\%). The average age of the examined sample is 38.3 years ( $\min .16$ and max. 82 years).

Data collection took place in the form of a questionnaire in the course of 2016-2021 in two ways. 291 samples were collected by field survey of clients of non-profit organisations Finanční tíseň o.p.s and Dečko Liberec, o.p.s. Another 323 samples were collected by means of an online questionnaire at www.povertylife.com and with the support of non-targeted online promotion on the Internet and social networks. 


\section{Data and Measurements}

Out of a total of 615 respondents, samples with missing data were excluded from the data set. The resulting sample size therefore equalled 599 respondents. The data were analysed using the STATA 16 statistical software. Data processing included mainly the categorisation of the age of the respondents into the following age groups: $0-29 ; 30-39 ; 40-49 ; 50-59$; over 60 years. Other data have not been modified.

Discounting was tested using two rewards (a small reward: CZK 100 / CZK 110 and large reward: CZK 100,000 / CZK 110,000) and in two-time horizons (today against a delay of 1 day; today against a delay of 1 month). The respondent was asked to decide whether they would prefer to receive the amount today or wait until tomorrow and in the second case today or wait for one month. The design of the experiment is based on similar psychological studies.

\section{Analyses}

The association study focused on the statistical analysis of the contingency table. First, we verified the fulfilment of the prerequisites for the use of the independence test in the contingency table (Pearson chí ${ }^{2}$ test). The prerequisites (i.e., the frequency of the examined variable in the contingency table was not less than 5 and none of the expected frequencies was less than 1) were always fulfilled.

After performing the independence test, we continued by evaluating the strength of the relationship between the two variables. The Cramer $V$ was used to derive the strength of the relationship. If the Cramer $V$ was in the range of $0.10-0.3$, the relationship was deemed weak. For the four-field table, we also evaluated the relative risk (RR) and chance of occurrence $(\mathrm{OR})$, including the reliability interval.

\section{Hypotheses}

The key hypotheses assume that patience is negatively affected by increasing age i.e., the older an individual is, the less patient they are, as they realise the increasing probability of death, which increases in direct proportion to age. The basic hypotheses tested in the experiment were as follows:

- H1: Respondents in the age group of 0-29 years are more patient than in the age groups of over 30 years.

- H2: Respondents in the age group of 0-29 years are more patient than respondents in the $60+$ age group.

- H3: Patience decreases with increasing age.

\section{Results}

The results of the experiments are processed for all 4 examined scenarios:

Scenario 1CZK 100 today or CZK 110 tomorrow (+1 day)

Scenario 2CZK 100 today or CZK 110 in a month's time (+ 1 month)

Scenario 3CZK 100,000 today or CZK 110,000 tomorrow (+1 day)

Scenario 4CZK 100,000 today or CZK 110,000 in a month's time (+ 1 month) Hypothesis $\mathrm{H} 1$ : Respondents in the age group of $0-29$ years are more patient than in the
age groups of over 30 years. 
Scenario 1: Individuals in the age group of 0-29 years are 1.397 times more likely to be more patient than individuals aged $30+$ years: $p=0.02346 ; R R=1.397 ; \mathrm{Cl}(1.029 ; 1.896)$; $O R=1.625$; $\mathrm{Cl}(1.064 ; 2.479)$. However, the relationship between patience and the compared age groups is at the lower limit - the Cramer's $V=-0.092$, which indicates a very weak relationship.

Scenario 2: Individuals in the age group of 0-29 years are 1.399 times more likely to be more impatient than individuals in the age group of $30+$ years: $p=0.0084 ; R R=1.399 ; \mathrm{Cl}(1.080$; 1.813); OR=1.643; $\mathrm{Cl}(1.135 ; 2.378)$. However, the relationship between impatience and the compared age groups is at the lower limit - the Cramer's $V=0.1081$, which is a stronger relationship than in Scenario 1, but the absolute value is still very low.

Scenario 3: Individuals in the age group of 0-29 years are 1.972 times more likely to be more patient than individuals aged $30+$ years: $p=0.002$; $R R=1.972$; $\mathrm{Cl}(1.212 ; 3.208)$; $O R=2.527$; $\mathrm{Cl}(1.387 ; 4.598)$. However, the relationship between patience and the compared age groups is at the lower limit - the Cramer's V $=-0.1258$, which is a stronger relationship than in Scenario 1 or 2.

Scenario 4: In this case, no relationship was found between age groups and patience. The independence test did not confirm the relationship between the examined quantities $(p=0.088$, Cramer's V: 0.0698)

\section{Hypothesis H2: Respondents in the age group of $0-29$ years are more patient than respondents in the $60+$ age group.}

Scenario 1: Individuals in the age group of 0-29 years are 1.317 times more likely to be more patient than individuals aged $60+$ years: $p=0.0032 ; R R=1.317 ; \mathrm{Cl}(1.062 ; 1.633) ; O R=2.617$; $\mathrm{Cl}(1.408 ; 4.870)$. The relationship between impatience and the compared age group is weak: Cramer's V $=-0.1882$.

Scenario 2: In this case, no relationship was found between age groups and patience. The independence test at the 0.05 reliability level did not confirm any relationship between the examined quantities ( $p=0.0844$, Cramer's V: 0.1128$)$.

Scenario 3: Individuals in the age group of 0-29 years are 1.583 times more likely to be more patient than individuals aged $60+$ years: $p=0.0016$; $R R=1.583 ; \mathrm{Cl}(1.087 ; 2.306) ; O R=3.800$; $\mathrm{Cl}(1.724 ; 8.380)$. The relationship between impatience and the compared age group is weak: Cramer's V $=-0,2093$.

Scenario 4: Individuals in the age group of 0-29 years are 1.297 times more likely to be more patient than individuals aged $60+$ years: $p=0.0009 ; \mathrm{R}=1.297 ; \mathrm{Cl}(1.098 ; 1.532) ; \mathrm{OR}=2.720$; $\mathrm{Cl}(1.534 ; 4.823)$. The relationship between impatience and the compared age group is weak: Cramer's $\mathrm{V}=-0.2119$, yet it is the highest among the previous analyses.

\section{Hypothesis H3: Patience decreases with increasing age.}

Scenario 1: Based on the analysis of the contingency table and the independence test, it may be stated that for a small amount with a delay of 1 day, there is a higher proportion of more patient individuals in the age group 0-29 years than in the age category of $60+$ years, and at the same time, with the older age, there is a lower proportion of more patient individuals, or the relative number of the impatient increases $(p=0.029$, Cramer's $V=0.1348)$.

Scenario 2: This scenario (verification of patience for a small amount with a 1-month delay period) did not show a relationship between age groups and patience $(p=0.066$, Cramer's V: 0.1205). 
Scenario 3: Individuals who were offered CZK 100,000 today or CZK 110,000 one day later show significant differences in patience between age groups. While individuals in the age group of $0-29$ years show patience in $93.14 \%$ of cases, in the age category $60+$ years, it is only $78.13 \%$, and in the age category of $50-59$ years even only $69.81 \%$. Thus, it can be stated in the second scenario that with increasing age, a decrease in patience was observed in the examined respondents, while the lowest was in the age category of 50 to 59 years $(p=0.000$; Cramer's V $=0.2134)$.

Scenario 4: In this scenario, individuals were offered CZK 100,000 today or CZK 110,000 in a month's time. In comparison to Scenario 3, the overall patience rate decreased by approximately 20 percentage points due to a delay of 1 month. In the case of this offer, the highest patience was recorded among individuals in the age category of $30-39$ years $(73.55 \%)$, yet also individuals in the age category of $0-29$ years showed a significantly higher proportion of the patient $(70.59 \%)$ than individuals in the age category of $60+$ years $(46.88 \%)$. It was confirmed in the examined sample of individuals that patience decreases with increasing age $(p=0.001$; Cramer's $V=0.1753)$.

\section{Discussion}

The aim of the research was to clarify the behaviour of individuals of time discounting or patience according to age groups. The strongest relationship between patience and age was observed in a situation where individuals were offered CZK 100,000 immediately or CZK 110,000 a day later. However, the strength of the relationship between the variables was similar for the same amounts, yet with a one-month delay.

In all scenarios, individuals were offered an increase of $10 \%$ (after conversion to an increase in p.a., it was $120 \%$ and $3600 \%$ p.a.). By choosing the "today" option rather than a one-day or one-month delay, some have shown whether discounting is a sufficient or insufficient value for them. An increase of $120 \%$ p.a. or $3600 \%$ p.a. was most frequently sufficient for the younger generation (0-29 years) and vice versa, the higher the age of individuals, the more the discounting ceased to be sufficient for them.

In the case of Scenario 3, only $12.69 \%$ of the whole sample of individuals were those for whom the increase in the reward was not sufficient to wait until the following day. Therefore, these individuals have a subjective discount rate (in annual terms) higher than $3600 \%(10 \% \times 360$ days). In the age category of $0-29$ years, these individuals represented only $6.86 \%$, while in the age category of $50-59$ years, they represented $30.19 \%$ or $21.88 \%$ in the case of the category of $60+$ years.

In scenario 4 , a $10 \%$ increase in the reward over a month was insufficient for $34 \%$ of individuals to wait a full month for the increased amount. Therefore, these individuals have a subjective discount rate (in annual terms) higher than $120 \%$ (10\% x 12 months). In the age group of $0-29$ years, these individuals represented only in $29.41 \%$ of cases, while the least of them were found in the age group of $30-39$ years $(26.45 \%)$. On the contrary, the highest proportion of impatient individuals was found in the age group of $60+$ years $(53.13 \%)$; see Table 1.

Table 1: Share of persons with various subjective discount rates $\rho$ (large amounts of CZK 100,000):

\begin{tabular}{lcccc} 
Age category & $\mathbf{\rho}<\mathbf{1 2 0} \%$ & $\mathbf{1 2 0} \%<\boldsymbol{\rho}<\mathbf{3 6 0 0} \%$ & $\boldsymbol{\rho}>\mathbf{3 6 0 0} \%$ & Total \\
\hline 0-29 years & $70.59 \%$ & $22.55 \%$ & $6.86 \%$ & $100 \%$ \\
$30-39$ years & $73.55 \%$ & $16.83 \%$ & $9.92 \%$ & $100 \%$
\end{tabular}




\begin{tabular}{lllll}
$40-49$ years & $61.48 \%$ & $24.59 \%$ & $13.93 \%$ & $100 \%$ \\
$50-59$ years & $59.62 \%$ & $10.19 \%$ & $30.19 \%$ & $100 \%$ \\
$60+$ years & $46.88 \%$ & $31.25 \%$ & $21.88 \%$ & $100 \%$ \\
\hline
\end{tabular}

Source: Own calculations.

Unfortunately, the same overview of the relative frequencies of the subjective discount rate could not be compiled for discounting the lower value (CZK 100), as the data did not confirm the mutual relationship in cases of postponement of acquiring the reward by one month.

The study has its limits mainly in the fact that it examines only the discounting of the reward, rather than focusing on discounting from the perspective of deferral of consumption. Furthermore, we limited ourselves to discounting two rates (120\% and $3600 \%)$. We can only state whether the individuals' discounting is higher or lower than these thresholds. Another method of determining the subjective discount rate is to determine the amount at which they would defer the acquisition of the reward for a specific period (day, month, and year). Based on these experiments, it is then possible to depict the course of the reward discounting function more accurately. This was not the objective of this paper. The key for us was to determine the differences in discounting rewards between individuals of different ages.

Some studies indicate that older generations discount future rewards less than younger generations. However, other studies provide the opposite results (Löckenhoff, 2011, Green, L., Fry, A. F., \& Myerson, J. 1994), i.e., with increasing age, there is a higher willingness to wait to receive a reward. The second of the cited studies was based only on the examination of 36 individuals (12 children 11-12 years +12 university students +12 adults with an average age of 67.9 years). The authors cited the reason for their results as the improvement of intertemporal decision-making with increasing age (greater prudence). Our study was performed on a larger sample of individuals, and it can therefore be assumed that these results may have a higher validity. Other studies confirm that the different results between studies may be influenced by the fact that the young generation makes more impulsive decisions than the older one; see Read \& Read (2004).

In our research, it may be confirmed that individuals in the age group of 0-29 years are 1.583 times more likely to behave more impulsively than individuals aged $60+$ years: $p=0.0016$; $\mathrm{RR}=1.5833$; $\mathrm{Cl}(1.087 ; 2.306)$. Impulsive behaviour may affect the results of our original hypotheses. Individuals with less impulsive behaviour think better about their decisions and in experiments, and their answers may be more accurate, unlike hypothetically hasty decisions of impulsive individuals. Differences in behaviour between age groups have important repercussions on firms' decisions on hiring factors of productions as confirmed by Novotna (2021), on participation of individuals of different age in labour market (interesting results provided by Kaderabkova, 2020 or Grzeskowiak, 2020) or short and log term investment decisions (as confirmed by Hromada, 2021, Klieber, 2021, or Varinder). However, this aspect was not the main subject of this study, and therefore the topic was not further explored. Nevertheless, it may serve as an inspiration for further research.

\section{Conclusion}

We have analysed the data of 599 respondents who were specifically asked the classic questions of time discounting. There were 4 scenarios (a small amount without delay, a small amount with a delay of 1 month, a large amount without delay, and a large amount with a delay of 1 month). We tested a total of three basic hypotheses which were always statistically significant in three out of four scenarios. 
The results of the analysis of contingency and four-field tables indicated that in the age category of 0-29 years, there are relatively fewer impatient individuals than in other age groups. In accordance with the third hypothesis, it may be stated that a decrease in patience was observed in the respondents with increasing age. Rarely, among the least patient individuals were those who are in the age group of 50-59 years, yet most frequently in the age category of $65+$ years.

The results may be linked to the permanent income theory or life cycle theory. Both theories are similar in terms of the idea that income in a person's life is equal, and individuals are required to make savings in their young age and productive age, i.e., reduce their current consumption and postpone it to the future to secure income in their older age. This study indicates that the permanent income theory or life cycle theory may be based on a microeconomic view of the individual and the psychological factors (especially patience and impulsivity) affecting their decision-making. Impact of individual decision making on aggregate output and economic cycle was confirmed by many studies. Interesting results are presented e.g. in Čermáková (2021).

In addition, our conclusions have an impact on consumption and savings, for example in an economy where the population is aging. The results imply the opposite effect of impulsivity and patience. Thus, the conclusion of the study on 599 respondents may be simply summarised as follows: "With increasing age, impulsivity decreases and individuals' impatience increases".

\section{Acknowledgements}

This research was founded by grant number VŠE IGS F5/2/2020.

\section{Appendix}

Table 1A: Statistic Analysis (Hypothesis H1, Scenario 1)

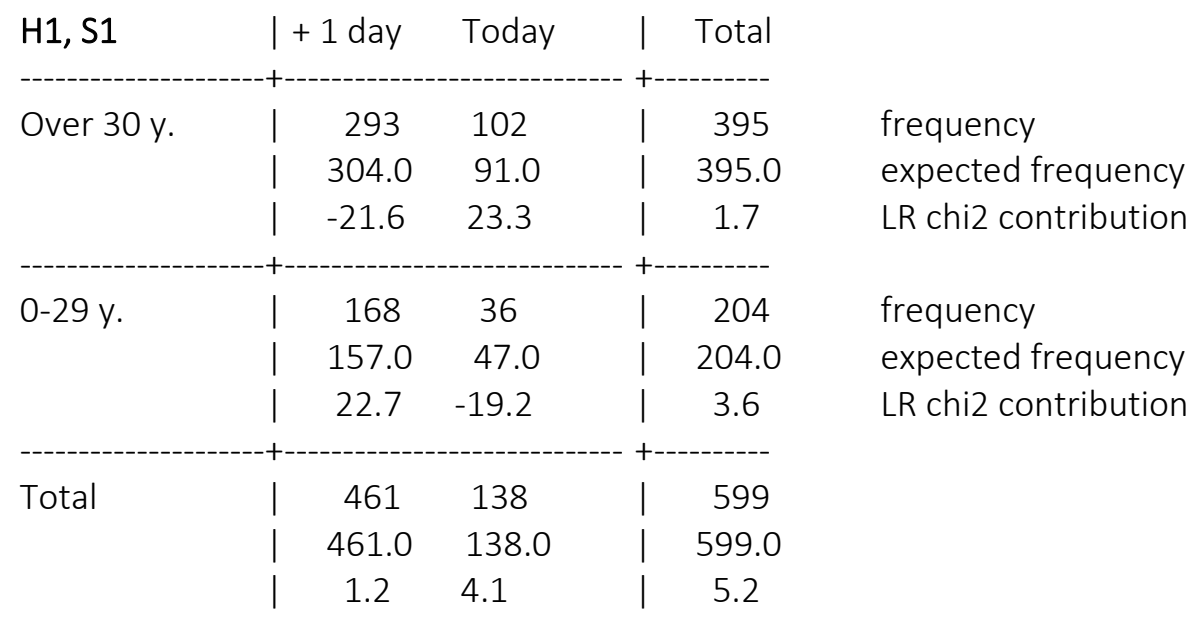

$\begin{array}{lll}\text { Pearson chi2(1) } & =5.0714 & \mathrm{p}=.024 \\ \text { likelihood-ratio chi2(1) } & =5.2365 & \mathrm{p}=.022 \\ \text { Cramér's V } & =-.0920 & \\ \text { Kendall's tau-b } & =-.0920 & \mathrm{ASE}=.039 \\ \text { RR (patience): } & =1.397 & \mathrm{Cl}:(1.029 ; 1.896) \\ \text { OR: } & =1.625 & \mathrm{Cl}:(1.064 ; 2.479)\end{array}$


Table 1B: Statistic Analysis (Hypothesis H1, Scenario 2)

\begin{tabular}{l|ccc|c} 
H1, S2 & $\mid$ + 1 month Today & Total \\
\hdashline Over 30 y. & 148 & 244 & 392 \\
& & 133.5 & 258.5 & 392.0 \\
& 30.5 & -28.1 & 2.3 \\
\hline $0-29$ y. & 55 & 149 & 204 \\
& & 69.5 & 134.5 & 204.0 \\
& -25.7 & 30.5 & 4.8 \\
\hline Total & 203 & 393 & 596 \\
& 203.0 & 393.0 & 596.0 \\
& 4.8 & 2.3 & 7.1
\end{tabular}

$\begin{array}{lll}\text { Pearson chi2(1) } & =6.9609 & \mathrm{p}=.008 \\ \text { likelihood-ratio chi2(1) } & =7.1042 & \mathrm{p}=.008 \\ \text { Cramér's V } & =.1081 & \\ \text { Kendall's tau-b } & =.1081 & \mathrm{ASE}=.040 \\ \text { RR (patience): } & =.715 & \mathrm{Cl}:(.551 ; .926) \\ \text { RR (impatience): } & =1.399 & \mathrm{Cl}:(1.080 ; 1.813) \\ \text { OR (patience): } & =.609 & \mathrm{Cl}:(.421 ; .881) \\ \text { OR (impatience) } & =1.643 & \mathrm{Cl}:(1.135 ; 2.378)\end{array}$

Table 1C: Statistic Analysis (Hypothesis H1, Scenario 3)

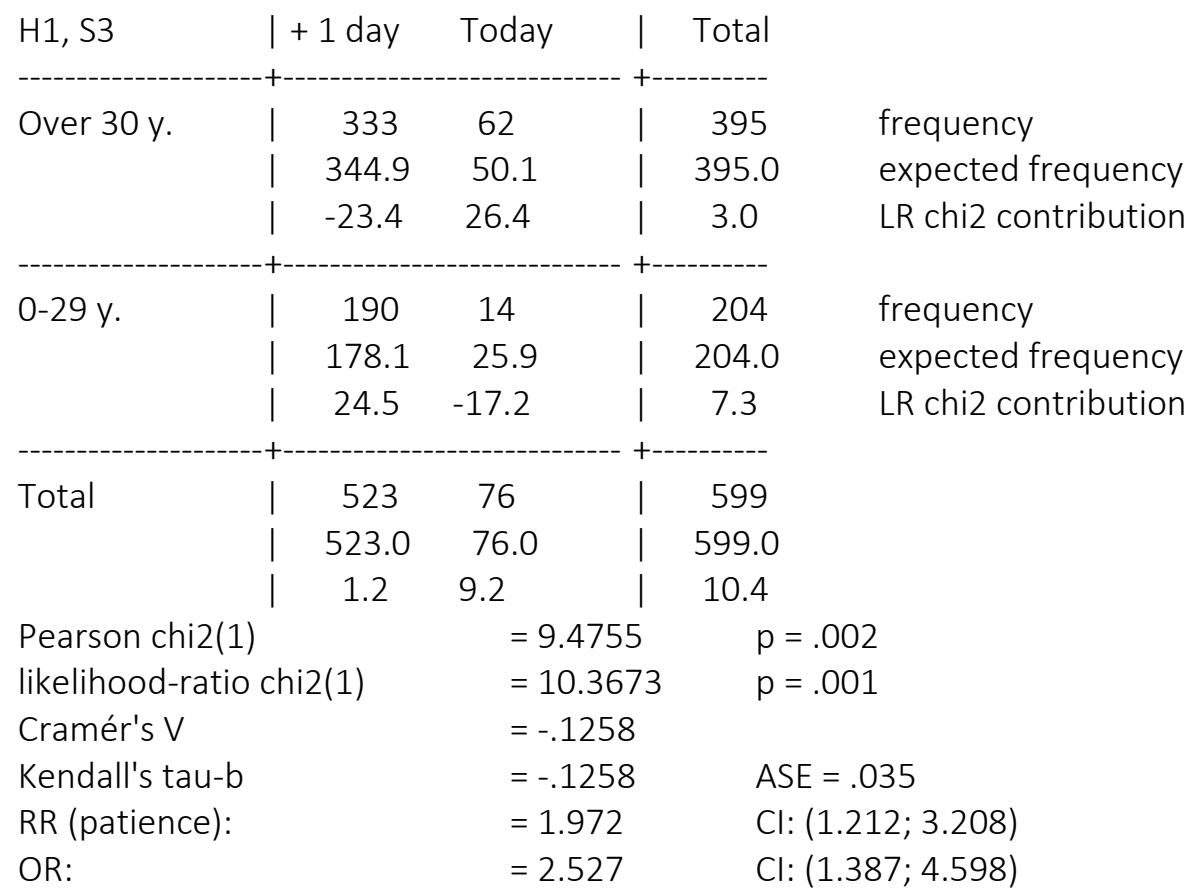

Table 1D: Statistic Analysis (Hypothesis H1, Scenario 4)

\begin{tabular}{|c|c|c|c|c|}
\hline $\mathrm{H} 1, \mathrm{~S} 4$ & | + 1 month & Today & | & Total \\
\hline \multirow[t]{3}{*}{ Over 30 y. } & 250 & 143 & | & 393 \\
\hline & 259.4 & 133.6 & 1 & 393.0 \\
\hline & -18.4 & 19.4 & | & 1.0 \\
\hline
\end{tabular}




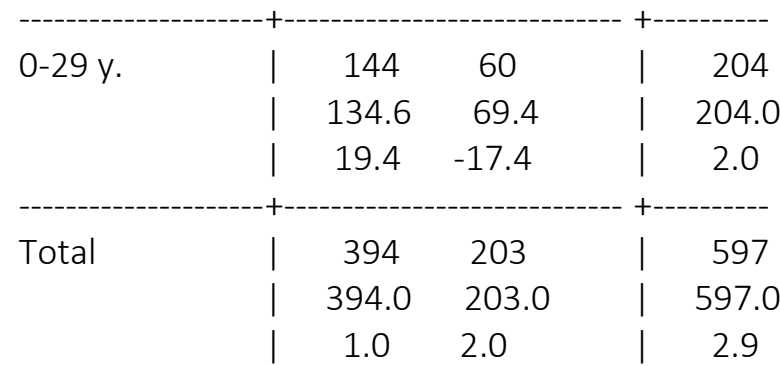

Pearson chi2(1)

$=2.9113$

$\mathrm{p}=.088$

likelihood-ratio chi2(1)

$=2.9472$

$p=.086$

Cramér's V

$=-.0698$

Kendall's tau-b

$=.0698$

ASE $=.040$

Table 2A: Statistic Analysis (Hypothesis H2, Scenario 1)

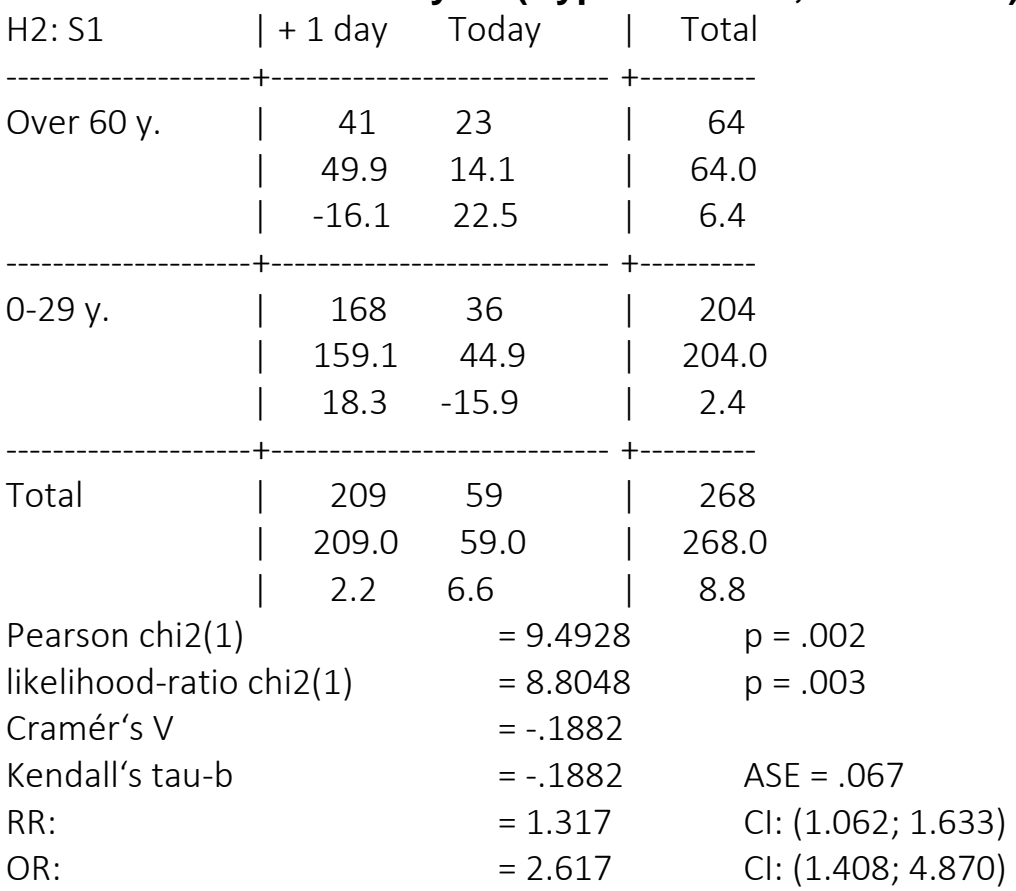


Table 2B: Statistic Analysis (Hypothesis H2, Scenario 2)

\begin{tabular}{|c|c|c|c|}
\hline $\mathrm{H} 2, \mathrm{~S} 2$ & | + 1 month & ר Today | & Total \\
\hline \multirow[t]{3}{*}{ Over 60 y. } & 25 & 39 & 64 \\
\hline & 19.1 & 44.9 & 64.0 \\
\hline & 13.4 & -11.0 & 2.5 \\
\hline \multirow[t]{3}{*}{$0-29 y}$. & 55 & 149 & 204 \\
\hline & 60.9 & 143.1 & 204.0 \\
\hline & | -11.2 & 12.0 & 0.8 \\
\hline \multirow[t]{3}{*}{ Total } & 80 & 188 & 268 \\
\hline & 80.0 & 188.0 & 268.0 \\
\hline & 2.2 & 1.1 & 3.3 \\
\hline \multicolumn{2}{|c|}{ Pearson chi2(1) } & $=3.4071$ & $p=.065$ \\
\hline \multicolumn{2}{|c|}{ likelihood-ratio chi2(1) } & $=3.2968$ & $p=.069$ \\
\hline \multicolumn{2}{|c|}{ Cramér's V } & $=.1128$ & \\
\hline \multicolumn{2}{|c|}{ Kendall's tau-b } & $=.1128$ & $\mathrm{ASE}=.064$ \\
\hline
\end{tabular}

Table 2C: Statistic Analysis (Hypothesis H2, Scenario 3)

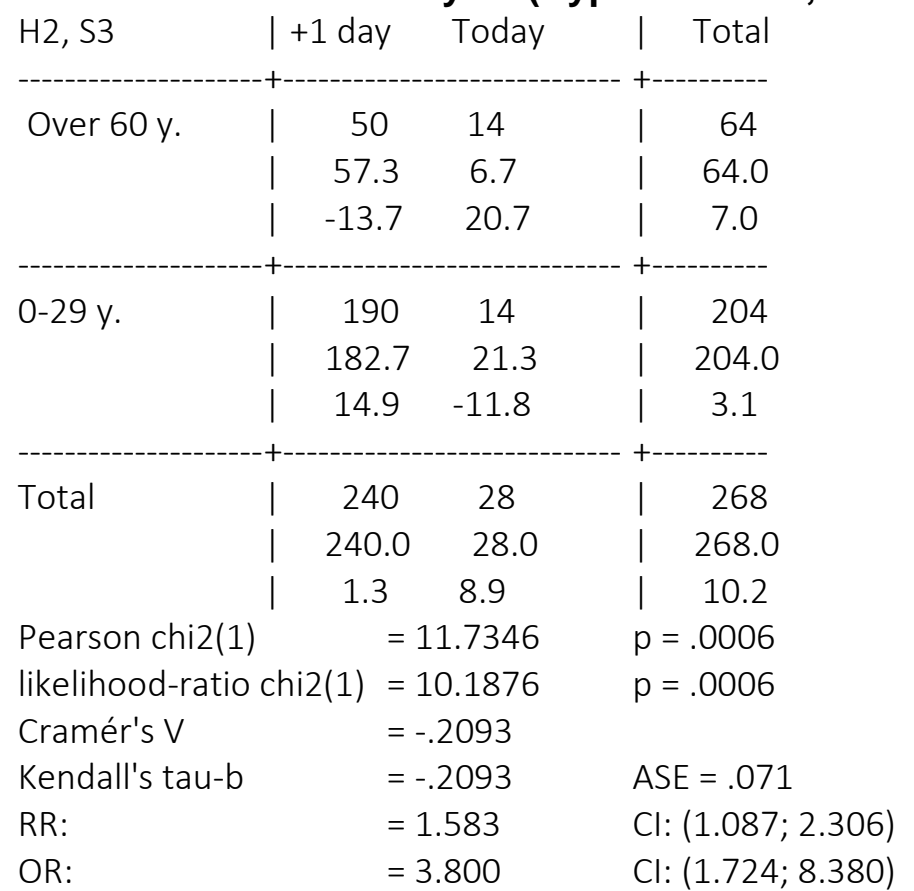

Table 2D: Statistic Analysis (Hypothesis H2, Scenario 4)

\begin{tabular}{|c|c|c|c|}
\hline $\mathrm{H} 2, \mathrm{~S} 4$ & | +1 month & Today & | Total \\
\hline \multirow[t]{3}{*}{60 a více let } & 30 & 34 & 64 \\
\hline & 41.6 & 22.4 & 64.0 \\
\hline & -19.5 & 28.2 & 8.7 \\
\hline \multirow[t]{3}{*}{ 0-29 let } & 144 & 60 & 204 \\
\hline & 132.4 & 71.6 & 204.0 \\
\hline & 24.1 & -21.1 & 3.0 \\
\hline \multirow[t]{2}{*}{ Total } & 174 & 94 & 268 \\
\hline & 174.0 & 94.0 & 268.0 \\
\hline
\end{tabular}




\begin{tabular}{|c|c|c|}
\hline 4. & 7.1 & 11.6 \\
\hline Pearson chi2(1) & $=12.0296$ & $p=.0005$ \\
\hline likelihood-ratio chi2(1) & $=11.6403$ & $p=.0005$ \\
\hline Cramér's V & $=-.2119$ & \\
\hline Kendall's tau-b & $=-.2119$ & ASE $=.063$ \\
\hline RR: & $=1.297$ & $\mathrm{Cl}:(1.098 ; 1.532)$ \\
\hline OR: & $=2.720$ & $\mathrm{Cl}:(1.534 ; 4.823)$ \\
\hline
\end{tabular}

Table 3A: Statistic Analysis (Hypothesis H3, Scenario 1)

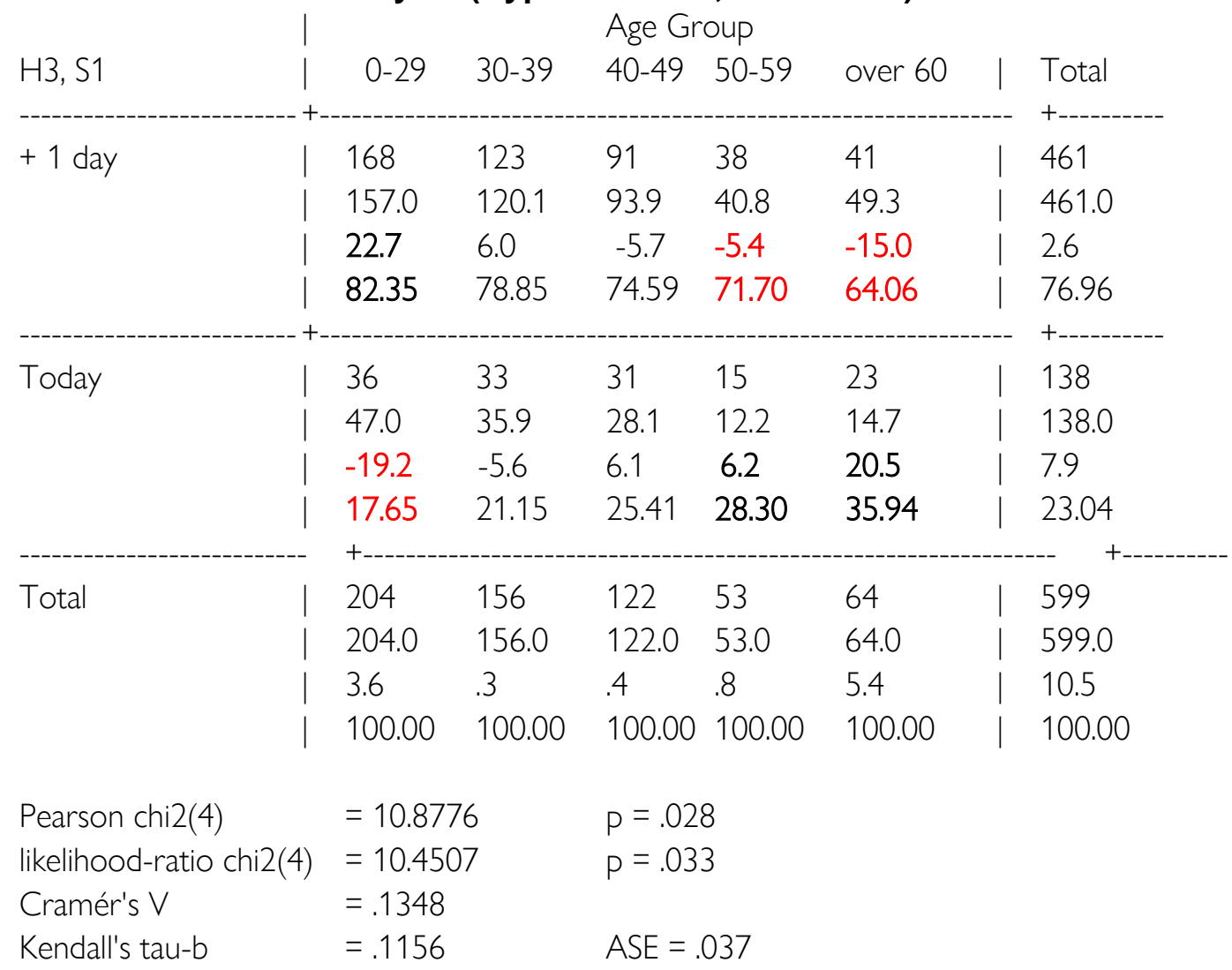

Table 3B: Statistic Analysis (Hypothesis H3, Scenario 2)

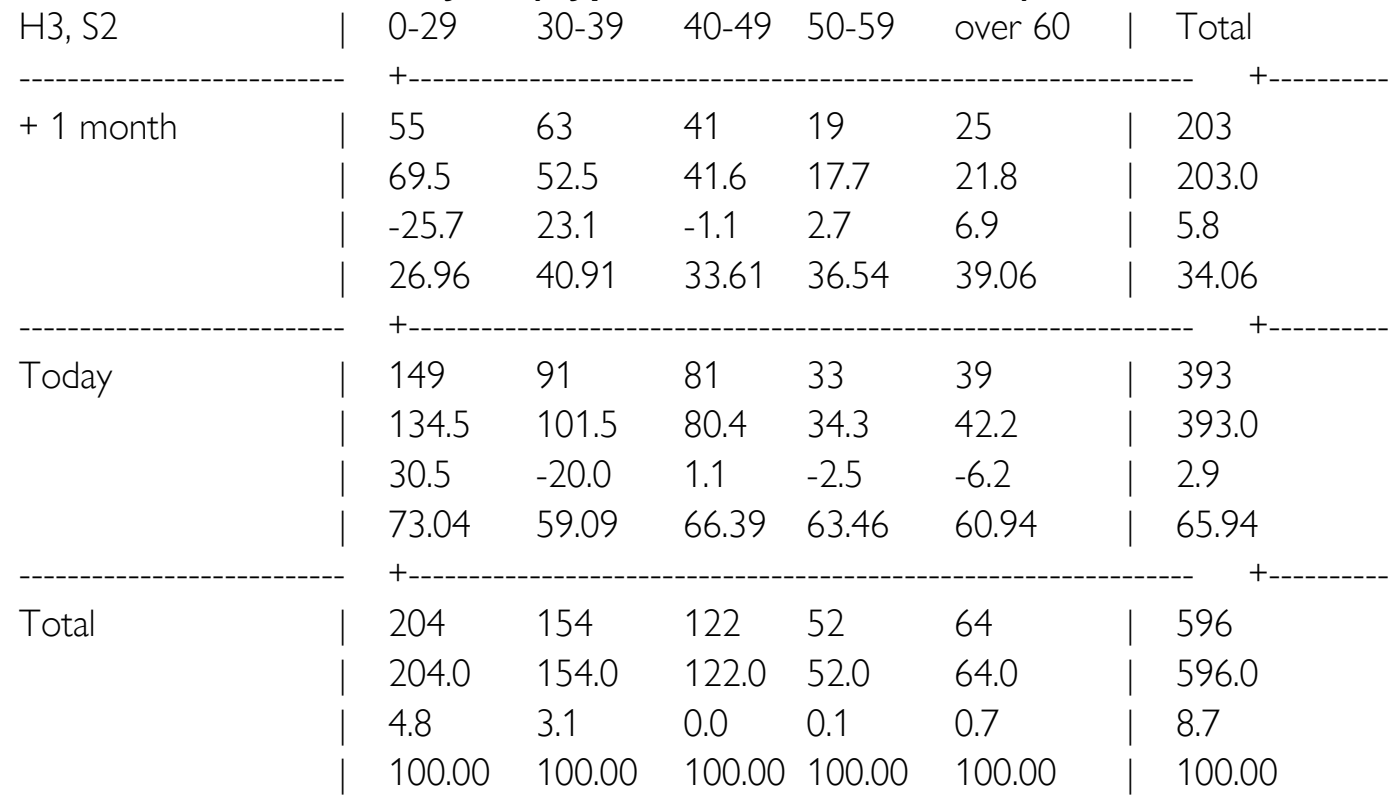




$\begin{array}{lll}\text { Pearson chi2(4) } & =8.6608 & \mathrm{P}=.070 \\ \text { likelihood-ratio chi2(4) } & =8.7365 & \mathrm{P}=.068 \\ \text { Cramér's V } & =.1205 & \\ \text { Kendall's tau-b } & =-.0718 & \text { ASE }=.037\end{array}$

Table 3C: Statistic Analysis (Hypothesis H3, Scenario 3)

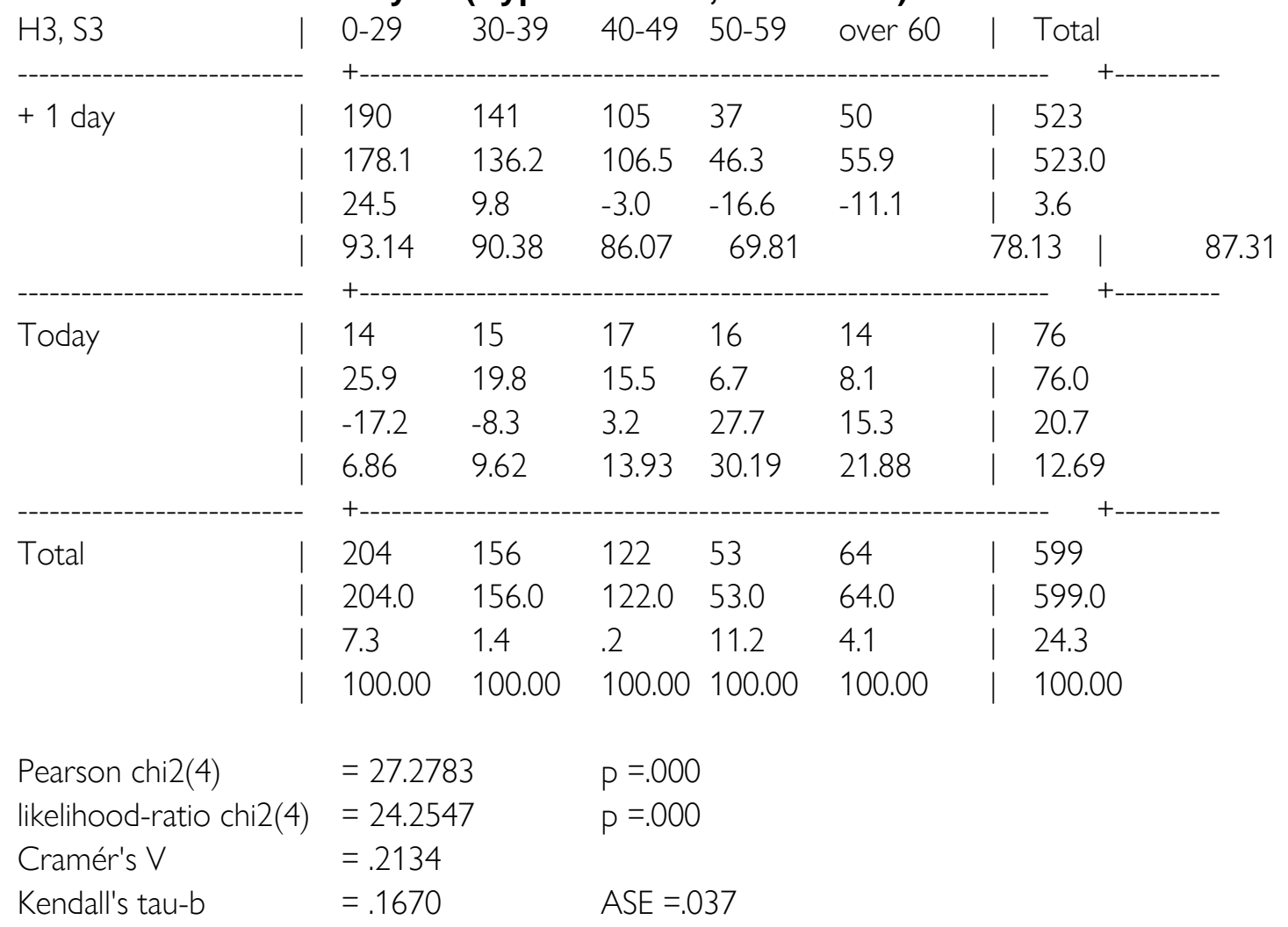

Table 3D: Statistic Analysis (Hypothesis H3, Scenario 4)

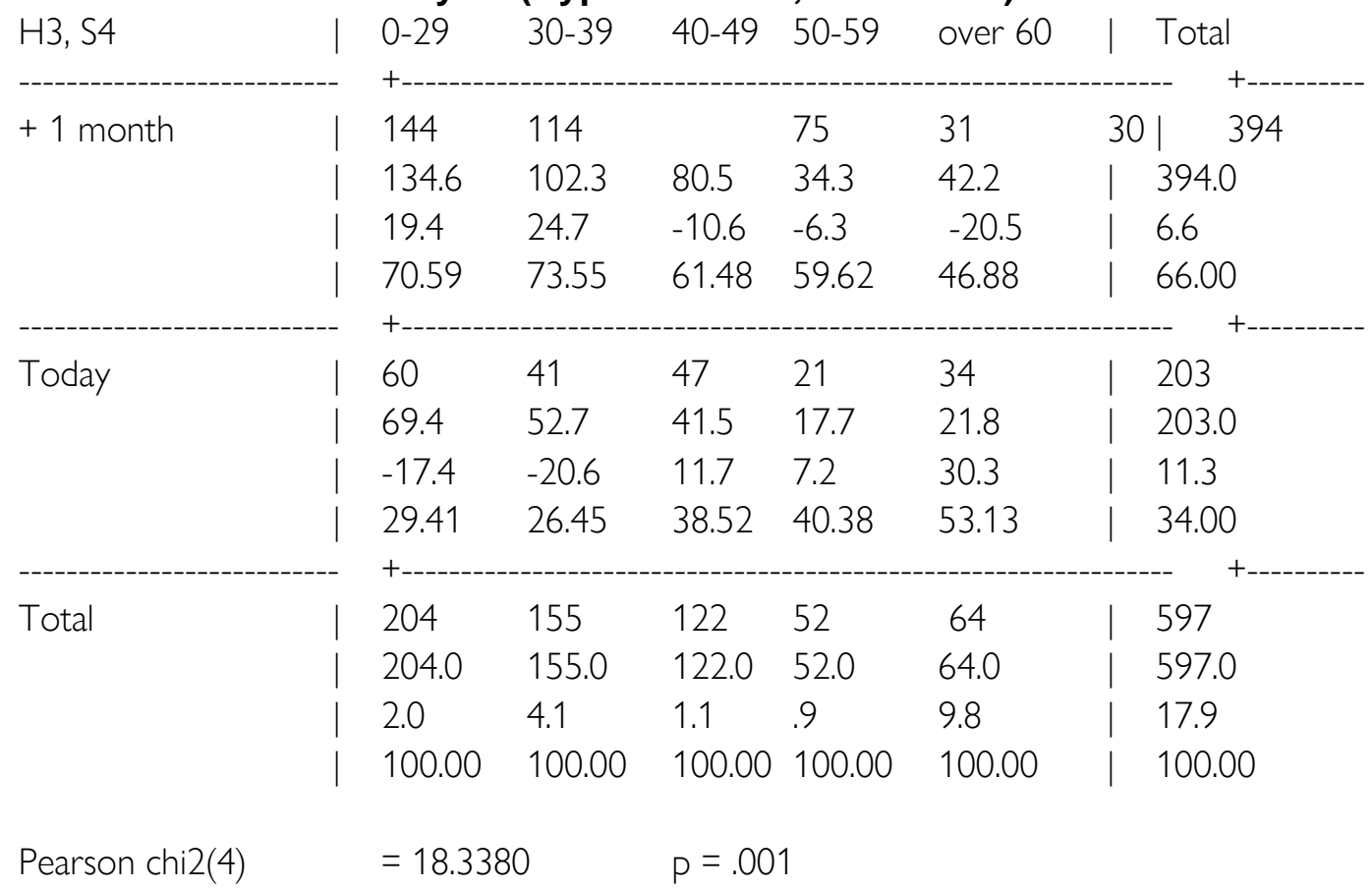




$\begin{array}{lll}\text { likelihood-ratio chi2(4) } & =17.8930 & \mathrm{P}=.001 \\ \text { Cramér's V } & =.1753 & \\ \text { Kendall's tau-b } & =.1285 & \text { ASE }=.038\end{array}$

\section{References}

AINSLIE, G. (1975) : Specious reward: a behavioral theory of impulsiveness and impulse control. Psychological bulletin, 82(4), 463.

Čermáková K, Bejček M, Vorlíček J, Mitwallyová H. Neglected Theories of Business CycleAlternative Ways of Explaining Economic Fluctuations. Data. 2021; 6(11):109. https://doi.org/10.3390/data6110109

Friedman, M. (1957) : The Permanent Income Hypothesis. A Theory of the Consumption Function. Princeton University Press. ISBN 978-0-691-04182-7.

Green, L., Fry, A. F., \& Myerson, J. (1994) : Discounting of delayed rewards: A life-span comparison. Psychological Science, 5, 33-36.

GRZEŚKOWIAK, A. (2020). Soft skills and earnings: evidence from a nationwide survey in Poland. International Journal of Economic Sciences, Vol. IX(1), pp. 102-120. , DOI: 10.52950/ES.2020.9.1.006

Halfmann, K., Hedgcock, W., \& Denburg, N. L. (2013) : Age-related differences indiscounting future gains and losses.Journal of Neuroscience, Psychology, andEconomics,6, 42-54. https://doi:10.1037/npe0000003

Harrison, G. W., Lau, M. I., \& Williams, M. B. (2002) : Estimating individual discount ratesin Denmark: a field experiment.American Economic Review, 92, 1606-1617. https://doi:10.1257/000282802762024674

HERRNSTEIN, R. J. (1981) : Self-control as response strength. In: Quantification of steady-state operant behavior. Amsterodam: Elsevier/North Holland Biomedical Press. pp. 3-20.

HROMADA, E., KRULICKY, T. Investing in Real Estate in the Czech Republic and Analyzing the Dependence of Profitability and Technical and Socio-Economic Factors. Sustainability. 2021; 13(18):10273. https://doi.org/10.3390/su131810273

KABLE, Joseph W., Karolina LEMPERT a David A. WOLK. (2019) : Factors affecting temporal discounting in older adults. Research Dialogue. TIAA Institute, 2019, (152), 1-19.

KADEŘÁBKOVÁ, B., JAŠOVÁ, E. 2020: COMPARATION OF THE ECONOMIC CYCLE ON LABOUR MARKET IN THE CONSTRUCTION INDUSTRY AND IN THE NATIONAL ECONOMY OF THE CZECHIA. Civil Engineering Journal Stavebni obzor,3/2020, DOI 10.14311/CEJ.2020.03.0024

KAHNEMAN, D. a A. TVERSKY. (1979) : Prospect Theory: An Analysis of Decision under Risk. Econometrica. Vol. 47, No. 2, pp. 263-292.

KAHNEMAN, D. a A. TVERSKY. (1984) : Choices, values, and frames. American Psychologist. Vol. 39, No. 4, pp. 341-350. DOI: 10.1037/0003-066X.39.4.341.

KAHNEMAN, D. a A. TVERSKY. (1991) : Loss Aversion in Riskless Choice: A reference-dependent model. Quartel Journal of Economics, November, p. 1039-1061.

KLIBER, P., RUTKOWSKA-ZIARKO, A. (2021). Portfolio choice with a fundamental criterion - an algorithm and practical applicationon - a computation methods and empirical analysis. International Journal of Economic Sciences, Vol. X(1), pp. 39-52. , DOI: 10.52950/ES.2021.10.1.003 
Li, Y., Baldassi, M., Johnson, E. J., \& Weber, E. U. (2013) : Complementary cognitivecapabilities, economic decision making, and aging. Psychology and Aging, 28(3),595-613. http://doi.org/10.1037/a0034172

LIU, P. , WOOD, S., HANOCH, Y. (2015) : Choice and Aging. Aging and Decision Making. Elsevier, 2015, 309-327. ISBN 9780124171480. Dostupné z: doi:10.1016/B978-0-12-417148-0.00015-7

LÖCKENHOFF, Corinna E. (2011) Age, time, and decision making: from processing speed to global time horizons. Annals of the New York Academy of Sciences. 2011, 1235(1), 44-56. ISSN 00778923. Dostupné z: doi:10.1111/j.1749-6632.2011.06209.x.

LOEWENSTEIN, George a Drazen PRELEC. (1992) : Anomalies in Intertemporal Choice: Evidence and an Interpretation. The Quarterly Journal of Economics. Vol. 107, No. 2, pp. 573-597.

MODIGLIANI, F. (1966) : The Life Cycle Hypothesis of Saving, the Demand for Wealth and the Supply of Capital. Social Research. 33 (2): 160-217.

NOVOTNÁ, M., VOLEK, T., ROST, M., \& VRCHOTA, J. (2021). Impact of technology investment on firm's production efficiency factor in manufacturing. Journal of Business Economics and Management, 22(1), 135-155. https://doi.org/10.3846/ibem.2020.13635

RAE, John. (1834). The Sociological Theory of Capital. 1. vyd. London: Macmillan and Co., 1905. Reprint originálu 1834.

Read, D., \& Read, N. L. (2004) : Time discounting over the lifespan.Organizational Behaviorand Human Decision Processes, 94,22-32. https://doi:10.1016/i.obhdp.2004

Richter, David; Mata, Rui (2018) : Age differences in intertemporal choice: U-shaped associations in a probability sample of German households, SOEP papers on Multidisciplinary Panel Data Research, No. 974, Deutsches Institut für Wirtschaftsforschung(DIW), Berlin

Roalf, D. R., Mitchell, S. H., Harbaugh, W. T., \& Janowsky, J. S. (2012). Risk, reward andeconomic decision making in aging.The Journals of Gerontology Series B:Psychological Sciences and Social Sciences,67, 289-298.https://doi:10.1093/geronb/gbr099

Samanez-Larkin, G. R., Mata, R., Radu, P. T., Ballard, I. C., Carstensen, L. L., \& McClure, S.M. (2011). Age differences in striatal delay sensitivity during intertemporal choice inhealthy adults. Frontiers in Neuroscience, 5, 126.https://doi:10.3389/fnins.2011.00126

SAMUELSON, P. A. (1937). A note on measurement of utility. Review of Economic Studies. Vol. 4, pp. 155-161.

VARINDER G., FUK CHANG LI, MATOVU, Ch. (2020). Analysis of Factors that Influence Financial Literacy of Millennials in Canada. International Journal of Economic Sciences, Vol. IX(1), pp. 83101. , DOI: 10.52950/ES.2020.9.1.005

Whelan, R., \& McHugh, L. A. (2010). Temporal discounting of hypothetical monetaryrewards by adolescents, adults and older adults.The Psychological Record, 59, 247-258. https://doi.org/10.1007\%2Fbf03395661 